\title{
Microglia Development and Maturation and Its Implications for Induction of Microglia-Like Cells from Human iPSCs
}

\author{
Johannes Wurm ${ }^{1}\left(\mathbb{D}\right.$, Henna Konttinen ${ }^{2}\left(\mathbb{D}\right.$, Christian Andressen ${ }^{1}$, Tarja Malm ${ }^{2}$ and Björn Spittau ${ }^{1, *}$ \\ 1 Anatomy and Cell Biology, Medical School OWL, Bielefeld University, 33615 Bielefeld, Germany; \\ johannes.wurm@uni-bielefeld.de (J.W.); christian.andressen@uni-bielefeld.de (C.A.) \\ 2 Neuroinflammation Research Group, A.I. Virtanen Institute for Molecular Sciences, University of Eastern \\ Finland, 70211 Kuopio, Finland; henna.konttinen@uef.fi (H.K.); tarja.malm@uef.fi (T.M.) \\ * Correspondence: bjoern.spittau@uni-bielefeld.de; Tel.: +49-521-10686512
}

Citation: Wurm, J.; Konttinen, H.; Andressen, C.; Malm, T.; Spittau, B. Microglia Development and Maturation and Its Implications for Induction of Microglia-Like Cells from Human iPSCs. Int. J. Mol. Sci. 2021, 22, 3088. https://doi.org/ $10.3390 /$ ijms 22063088

Academic Editor: Jacopo Meldolesi

Received: 18 February 2021

Accepted: 15 March 2021

Published: 17 March 2021

Publisher's Note: MDPI stays neutral with regard to jurisdictional claims in published maps and institutional affiliations.

Copyright: (c) 2021 by the authors. Licensee MDPI, Basel, Switzerland. This article is an open access article distributed under the terms and conditions of the Creative Commons Attribution (CC BY) license (https:/ / creativecommons.org/licenses/by/ $4.0 /)$.

\begin{abstract}
Microglia are resident immune cells of the central nervous system and play critical roles during the development, homeostasis, and pathologies of the brain. Originated from yolk sac erythromyeloid progenitors, microglia immigrate into the embryonic brain parenchyma to undergo final postnatal differentiation and maturation driven by distinct chemokines, cytokines, and growth factors. Among them, TGF $\beta 1$ is an important regulator of microglial functions, mediating homeostasis, anti-inflammation, and triggering the expression of microglial homeostatic signature genes. Since microglia studies are mainly based on rodent cells and the isolation of homeostatic microglia from human tissue is challenging, human-induced pluripotent stem cells have been successfully differentiated into microglia-like cells recently. However, employed differentiation protocols strongly vary regarding used cytokines and growth factors, culture conditions, time span, and cell yield. Moreover, the incomplete differentiation of human microglia can hamper the similarity to primary human microglia and dramatically influence the outcome of follow-up studies with these differentiated cells. This review summarizes the current knowledge of the molecular mechanisms driving rodent microglia differentiation in vivo, further compares published differentiation protocols, and highlights the potential of TGF $\beta$ as an essential maturation factor.
\end{abstract}

Keywords: microglia maturation; TGF $\beta$; iPSC; microglia-like cells; hiMGLs

\section{Introduction}

Microglia are a specialized subset of myeloid cells and represent the resident immune cell population of the central nervous system (CNS). Recent achievements in deciphering the development and differentiation of microglia have resulted in various protocols to generate human microglia-like cells (hiMGLs) from human-induced pluripotent stem cells (hiPSCs) in vitro. Although these approaches result in hiMGLs that-at least partiallyshare the molecular signatures with human microglia in vivo, available differentiation protocols should consider recent findings elucidating microglia development and maturation in vivo. Here, we summarize the mechanisms of microglia differentiation in mice and compare various protocols using hiPSCs to generate hiMGLs in vitro. Special focus is given on the role of transforming growth factor $\beta 1$ (TGF $\beta 1$ ), its essential functions during microglia maturation, and its potential as an indispensable factor for the generation hiMGLs. The maturation of these cells closely mimicking resident human microglia is a prerequisite for future functional studies and may also pave the way for future microglia replacement strategies in humans.

\section{Mouse Microglia Development and Maturation In Vivo \\ 2.1. Mouse Microglia Origin and Development}

In contrast to other macrophage populations, microglia and CNS-associated resident macrophages (border-associated macrophages (BAMs)) originate from primitive 
macrophages at the first wave of hematopoiesis (for an overview of mouse microglia development and maturation, see Figure 1) [1]. These cells develop from early erythro-myeloid progenitors (EMPs) in the yolk sac at embryonic day E8.5 in a PU.1- and Irf8-dependent manner [2]. Unlike monocyte-derived macrophages, these primitive macrophages do not require the transcription factor Myb for their development [3]. They initially express the receptor tyrosine kinase c-Kit and lack the expression of CD45 and gradually lose c-Kit expression, while increasing the expression of CD45 during their further maturation [1,4]. Overlapping with the establishment of the primary blood circulation system, primitive macrophages start to migrate towards the neural tube to populate the developing brain and the spinal cord around E9.5, where they finally give rise to microglia [1,3]. This crucial migration step is dependent on the neuronal expression and secretion of Interleukin 34 (IL-34), which is sensed by the colony stimulating factor-1 receptor (Csf1r) being expressed by EMPs and developing microglia [1,5]. Moreover, microglial Csf1r signaling is further essential to mediate the survival of adult microglia [6]. In addition to the above-mentioned factors, the signal-dependent transcription factors Maf, Mef2c, and Sall1 are critical for proper microglia development [7-9].

Along with the establishment of the blood-brain-barrier (BBB) prenatally and after birth, the microglia population increases in the first postnatal weeks due to intraparenchymal proliferation and is further maintained in the adult CNS by a constant balance between microglial proliferation and apoptosis $[10,11]$. Under healthy physiological conditions, there is virtually no contribution of progenitors and/or monocytes recruited from peripheral blood circulation to maintain and support stable microglia numbers $[12,13]$. The gut microbiome, as well as the interaction of maturing microglia with various cell types within distinct developing CNS regions during the first postnatal weeks, is critical for the establishment of a region-specific microglia heterogeneity [14,15].

\subsection{Mouse Postnatal Microglia Maturation}

After prenatal microglial colonization of the brain parenchyma and subsequent preand postnatal microglial proliferation, the maturation process of these cells is further characterized by the induction and establishment of a microglia-specific gene expression pattern that distinguishes them from other macrophage populations [16-21]. These microgliaenriched genes are referred to as microglia homeostatic markers and are expressed by adult microglia under physiological conditions throughout different brain regions [22]. The expression of these genes, including Tmem119, Olfml3, P2yr12, Sall1, Hexb, Gpr34, Fcrls, or SiglecH, is upregulated within the first two postnatal weeks in mice and correlates with the activation of TGF $\beta$ signaling in microglia [18]. Immunohistochemistry and transgenic approaches have suggested neuron-derived TGF $\beta 1$ and TGF $\beta 2$ released by NG2-glia to be critically involved in triggering postnatal microglia maturation $[18,23]$. Further studies have clearly demonstrated that TGF $\beta 1$ is essential for microglia development [24] and maturation [25]. The deletion of TGF $\beta 1$ expression in the CNS [17], impairment of extracellular TGF $\beta 1$ processing and activation [26,27], or silencing of microglial TGF $\beta 1$ signaling by deletion of the TGF $\beta 1$ receptor Tgfbr 2 [28] resulted in a loss of microglia maturation, characterized by a lack of homeostatic microglia marker expression. Moreover, affected microglia further display an inflammatory phenotype, as evidenced by the increased expression of $A p o E, A x l, C y b b, C d 74, H 2-A a$, or $I l 1 b$, further emphasizing the importance of microglial TGF $\beta$ signaling to regulate microglia reactivity $[28,29]$. Although the functional significance of most of the homeostatic microglia markers is not well understood, the expression of these microglia-enriched genes strongly suggests their importance for mediating microglia functions, especially under physiological conditions [22,25]. This hypothesis is further supported by recent reports demonstrating the expression of the purinergic receptor $P 2 r y 12$ to be essential to promote microglial-driven neuroprotection and to support neuronal functions by dynamic interactions with synapses, as well as the microglia-mediated maintenance of BBB integrity after cerebrovascular damage $[30,31]$. Although TGF $\beta 1$ and microglial TGF $\beta$ signaling have been well established as crucial 
drivers of postnatal microglia maturation, it is likely that further molecular and cellular cues might be involved in final microglia differentiation and maturation processes in mice and humans. In addition, recent reports have described astrocyte-derived IL33 and the presence of $\mathrm{CD}^{+} \mathrm{T}$ cells in the CNS to be of critical importance for postnatal microglia maturation [32,33]. These recent studies indicate the molecular complexity involved in microglia maturation and further underpin the importance of future studies aiming to elucidate these mechanisms controlling the terminal developmental process.

E7.5 - E9.5
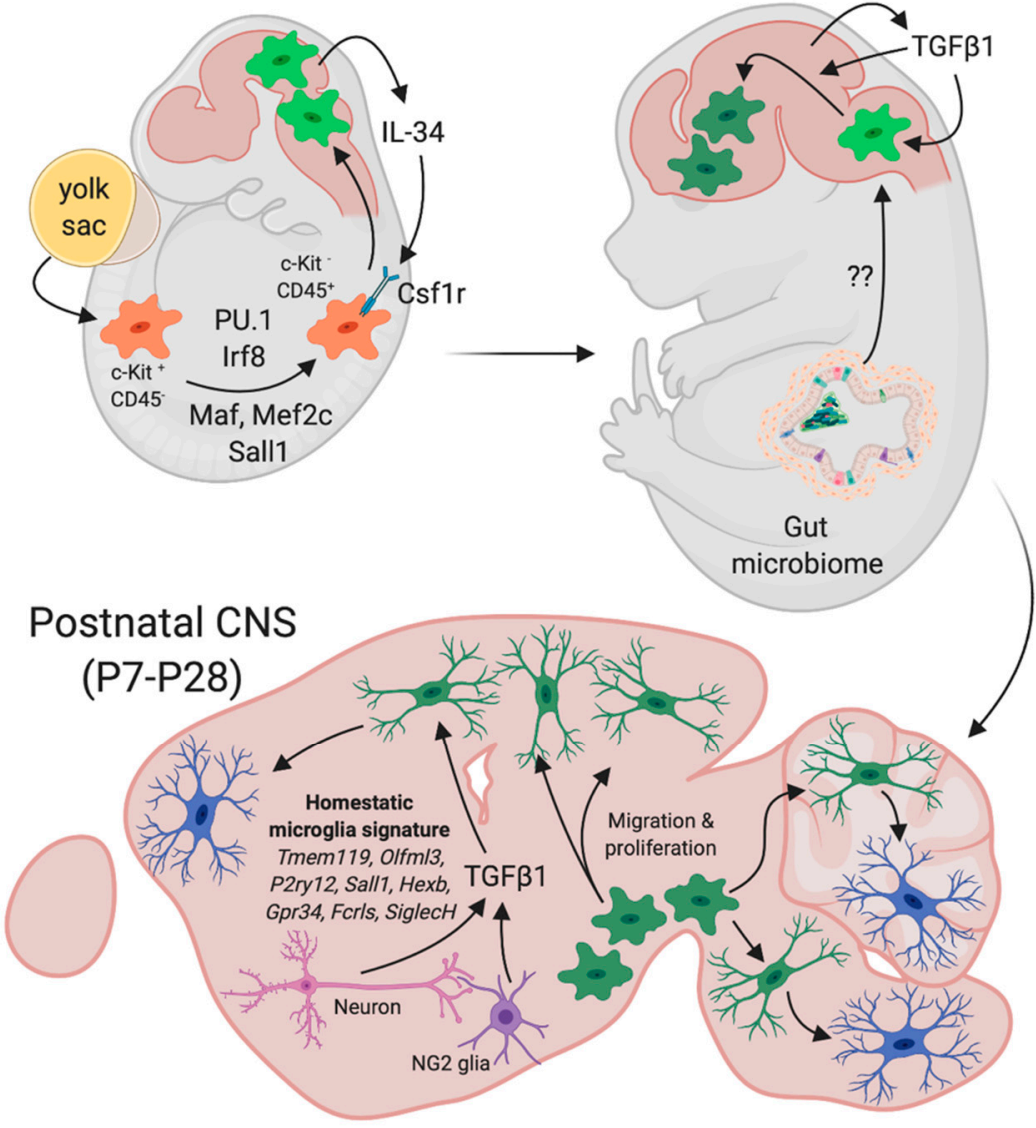

Figure 1. Molecular mechanisms underlying mouse microglia development and maturation in vivo. The figure was created using BioRender. Available online: https://biorender.com (accessed on 17 March 2021).

\subsection{Functional Consequences of Impaired Microglial Maturation}

Even though it is evident that microglia play a role in various CNS pathologies [22,34], although their exact role is not established in disease progression, still, their functions during CNS development and maintenance under physiological conditions remain unclear and is a major challenge in the microglia field. To date, microglia have been demonstrated to play important roles during pre- and postnatal CNS development by performing the synaptic pruning and active control of neuronal circuit formation [35-37], support of neuron survival and oligodendrocyte-mediated postnatal myelination [38,39], and promotion of learning-dependent synapse formation and maintenance of synapse function and integrity $[40,41]$. It is likely that these processes only represent a part of the full functional repertoire of microglia and that future studies will shed light on additional essential microglia functions in health. Furthermore, the above-mentioned recently found microglia roles suggest that impaired microglial maturation could also have detrimental consequences for postnatal CNS development. 
Indeed, the loss of microglial TGF $\beta$ signaling has been described to result in the development of spastic motor deficits as a consequence of impaired postnatal myelination of grey and white matter tracts, which is caused by disturbed oligodendrocyte maturation [28]. Moreover, in the presence of immature microglia, a substantial loss of cortical inhibitory interneurons has been demonstrated [28]. Supporting the hypothesis that the impairment of microglial maturation has detrimental effects on CNS development, the postnatal depletion of microglia did not result in the phenotypes observed in mice with immature microglia [28]. Taken together, these results underline the importance of the establishment of the homeostatic microglia-enriched gene expression signature for CNS development and postnatal maturation. This further suggests that a full microglia maturation phenotype needs to be induced in microglia-like cells generated from human iPSCs for subsequent functional analyses and/or replacement studies to better mimic the full spectrum of in vivo microglia.

\section{Generation of Human Microglia-Like Cells (hiMGLs) from Human-Induced Pluripotent Stem Cells (hiPSCs)}

The current knowledge about microglia development is mainly based on experimental animal studies performed in rodents with minor support from a few studies of aborted human embryos [42,43]. Although human and rodent microglia share most of their key functions and expression profiles, differences at a regulatory level have been identified. Pathways primarily involved in the modulation of microglial immune responses, such as the TGF $\beta$-mediated suppression of the human leukocyte antigen (HLA) expression [44], can only be detected in mouse models. By contrast, several immune genes, including $F C \gamma$, TAL1 and IFI16 [45], SIGLEC-11 [46], and SIGLEC-3 [47], have been identified exclusively in human microglia. The further identification of human-specific microglia expression profiles and resulting biological properties under physiological and pathological conditions may be implicative for future therapeutic approaches.

However, all comparative studies may be influenced by the challenging isolation of homeostatic human microglia that are commonly derived from post-mortem brains or disease-associated surgical biopsies. Under these conditions, senescence or pathologyassociated cues may influence the transcriptional and functional setting of the analyzed human microglia, e.g., their transition into activated states impeding the mouse and human-model, comparability. Additionally, as adult human microglia seem to be less proliferative than their mouse homologues $[48,49]$ and the survival of microglia from small biopsies is poor, in vitro analysis is limited to very low cell numbers that are not enough for comparable functional analysis. Importantly, it has to be taken into account that these primary cultures are not necessarily restricted to brain parenchymal-derived microglia, but may be "contaminated" by peripheral myeloid populations, possibly contributing to the above-mentioned heterogeneity.

In order to solve this problem, immortalized human microglial cell lines were established in the 1990s, including Hupglia [50], HMO6 [51], CHME5, and HMC3 [52]. However, these lines only partially reflect human microglia properties due to the loss of some antigenic characteristics critically involved in proliferation and homeostasis [53].

Increasing knowledge about the key molecules triggering microglial differentiation, maturation, and homeostatic signaling has enabled the development of hiMGL generated from hiPSC. Since 2016, a plethora of protocols have been established aiming at the in vitro generation of mature microglia-like cells mimicking their primary human counterparts concerning the expression of characteristic signature genes and functionality, including proliferation, migration, motility, integration into neural tissue, inflammatory reactions, and phagocytosis [54-65].

\subsection{Differentiation into Microglia Progenitors In Vitro}

Most of the published differentiation protocols try to mimic the in vivo developmental stages of human microglia by sequentially exposing hiPSCs to cytokines and growth factors, 
by adjusting the oxygen levels and/or progenitor isolation based on fluorescence-activated cell sorting (FACS) or magnetic-activated cell sorting (MACS).

The differentiation steps are summarized in Figure 2 and comprise the mesodermal differentiation of hiPSC into hemangioblasts and later into primitive hematopoietic stem cells (HPC) that are comparable to yolk sac EMPs during human microglia development [1,2].

A critical molecule inducing the mesodermal differentiation of hiPSCs is bone morphogenetic protein 4 (BMP4), which is used in nearly all protocols published. Additionally, mesodermal specification is supported by stem cell factor (SCF) or vascular endothelial growth factor (VEGF).

Wnt signaling has been implicated to affect HPC generation. While the initial differentiation of hemangioblasts is fostered by Wnt signaling [66], consecutive differentiation into primitive kinase insert domain receptor $(\mathrm{KDR})^{+} \mathrm{CD} 235^{+}$hematopoetic stem cells [67] that give rise to the yolk sac progenitors (in contrast to definitive $\mathrm{KDR}^{+} \mathrm{CD} 235^{-}$hematopoetic stem cells) is negatively regulated by Wnt-signaling. Therefore, Wnt-agonists were initially used for mesenchymal hiPSC differentiation, but treatment was switched to Wntantagonists reflecting the embryonic development $[60,64,68]$. Interestingly, this switch must occur in a very precise time window that, surprisingly, greatly differs from 18-24 h [68], $40-48 \mathrm{~h}$ [64], and 6 days [60] among the protocols.

In another study, definitive hematopoiesis was induced by the application of Wntactivator BIO and Activin-inhibitor SB431542 directly after mesodermal induction. This results in a significantly decreased number of cells expressing the triggering receptor expressed on myeloid cells 2 (TREM2), further indicating that hiMGLs can only be generated using the primitive hematopoietic stem cell lineage [56]. Using small molecules for the activation and inhibition of stage-specific pathways may be an opportunity for fine-tuning existing hiMGL differentiation protocols.

In a second step, sufficient myeloid progenitors can be generated in conventional monolayer cultures by using a time-dependent mix of cytokines, that comprises fms-like tyrosine kinase 3 (Flt3), granulocyte colony-stimulating factor (GCSF), IL-3, IL-6, SCF, VEGF, and thrombopoietin (TPO) $[57,62,63]$. Although their impact on mesodermal and myeloid differentiation is well characterized, individual and comprehensive implications on differentiation into hiMGLs are not well understood. However, differentiated hiMGLs that have been treated with VEGF during initial hematopoietic differentiation show enhanced CD45 and $\mathrm{C} \times 3 \mathrm{Cr} 1$ expression, implicating the need for fine-tuning the growth factor cocktails during early differentiation [69]. However, essential markers for homeostatic functions, including Iba1, CD11b, and P2RY12, have not been influenced in this case.

In addition to growth factor and cytokine treatment, reduced oxygen levels $\left(5 \% \mathrm{O}_{2}\right)$ during initial hematopoietic differentiation have also been shown to provide robust differentiation into myeloid progenitors $[55,59,60,64]$. Accordingly, it has been argued that $\mathrm{O}_{2}$ reduction may occur upon the formation of embryoid bodies (EBs) accounting for the progenitors in the inner cell mass [70]. This culture method is accompanied by cell-cell and / or cell-matrix interactions that may be beneficial for myeloid differentiation. Once the BMP4-driven mesenchymal differentiation of EBs is initiated, the growth factor and cytokine-cocktail for subsequent myeloid differentiation can be minimized to generate functional hiMGLs [56,58].

In contrast to other protocols, Muffat et al. grew iPSCs in a defined base medium chemically reflecting the cerebrospinal fluid and supplemented purely with CSF1 and IL-34, which are commonly not used until the terminal microglia differentiation. Nevertheless, EB formation spontaneously results in the formation of NPC spheroids, but also yolk sac-EBs, showing myeloid expression profiles [54].

As a result of hematopoietic and subsequent myeloid differentiation, the cells start to express CD117 and CD34 followed by CD235, CD41 [54,55,60,64], CD43 [55,59,62], and CD14 $[57,63]$. The time of appearance of myeloid progenitors greatly differs among protocols, ranging from 8 to 30 days, depending on the broad or frugal use of stage-specific growth factors and cytokines [58,64]. 


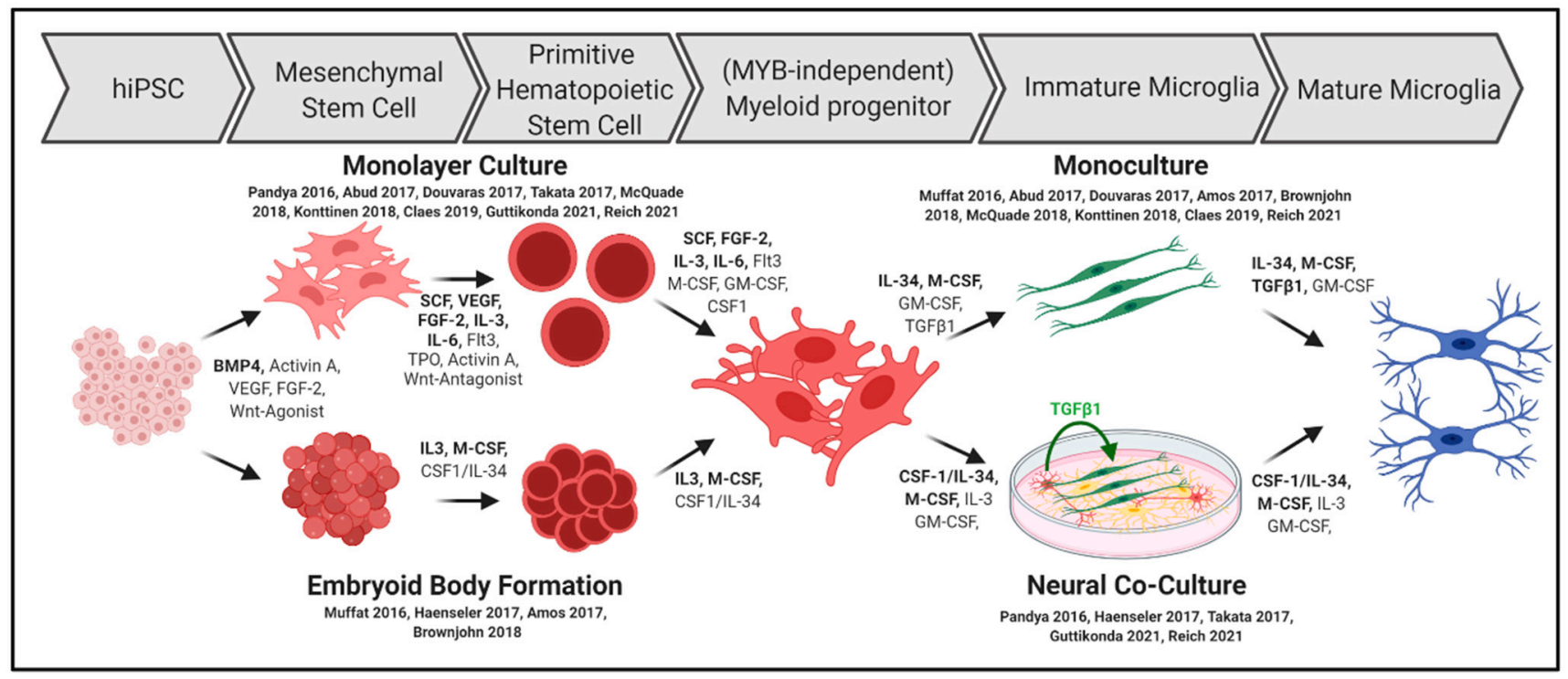

Figure 2. Basic differentiation strategies of iPSCs into hiMGLs indicating different culture methods and used signaling molecules, cytokines, and growth factors. The figure was created using BioRender. Available online: https://biorender.com (accessed on 17 March 2021).

\subsection{Final Microglia Differentiation and Maturation In Vitro}

The final microglia differentiation is mainly induced by switching the cytokine cocktail to IL-34 and macrophage colony stimulating factor (MCSF) for at least 10 to 30 days, in accordance with in vivo observations of microglia survival to be dependent on the activation of colony stimulating factor 1 receptor (CSF1R) [55,58,62-64]. As IL-34 instead of its natural ligand colony stimulating factor (CSF1) has been shown to play a major role in microglial differentiation in mice $[1,71,72]$, this cytokine has been used in most protocols at high concentrations $(100 \mathrm{ng} / \mathrm{mL})$, and the removal of this factor leads to depletion of the hiMGLs [58].

IL-34 and MCSF in combination lead to the expression of MERTK, ITGB5, CX3CR1, TGFBR1, IBA1, CD11b, and TMEM119, all of which are markers associated with immature and mature microglia [55]. Notably, a set of genes reported to be specific for the human microglial signature, including MERTK, GPR34, PROS1, C1QA, GAS6, and P2RY12 [17], has been detected at similar or even higher levels compared to primary adult human microglia $[58,59]$. This expression pattern greatly differs from blood-derived monocytes (PBMC) and PBMC-derived macrophages [57]. However, most of these genes are not only expressed in hiMGLs but also in hiPSC-derived macrophages [58], indicating that such genes may not be exclusively expressed by microglia.

CSF1 instead of IL-34 can also mediate hiMGL survival in vitro [54,60], highlighting the problem of putative species differences. As murine cytokines do not effectively bind to hiMGL receptors, mice carrying the human transgenes encoding CSF1 have been generated to solve this problem. In fact, a successful hiPSC integration into the mouse tissue was dependent on the presence of human CSF1, indicating the pivotal role of CSF1R stimulation for human microglial differentiation by its "natural" ligand instead of IL-34 [73]. In addition to recombinant CSF-1 or IL-34, which seem to be critically involved in hiMGL survival [58], their cardinal role for hiMGL differentiation remains questionable due to observations of final microglial differentiation, solely supported by coculture with human astrocytes [59]. Thus, it remains to be resolved whether this could be executed by an astrocytic secretome, as a mix of various factors, including granulocyte-macrophage colony-stimulating factor (GMCSF), IL-6, IL-8, and TGF $\beta$, that have been detected using an array for 32 human cytokines (not including IL-34 and MCSF) [74]. 


\subsection{TGF $\beta$ in Microglia Differentiation and Maturation In Vitro}

In the developing brain, TGF $\beta 1$ has been shown to regulate rodent microglial development, homeostasis, maturation, and survival $[17,24,25,75]$. These actions are mediated by the TGF $\beta$-receptor 1 (TGFBR1), which is highly expressed by both rodent microglia cultures and hiMGLs [55]. Therefore, TGF $\beta 1$ was considered as an important maturation factor for immature hiMGLs in distinct hiMGL differentiation protocols at concentrations ranging from 2 to $50 \mathrm{ng} / \mathrm{mL}$, and its effects have been addressed in detail (Figure 3) [55,56,62,76].

The withdrawal of TGF $\beta$ from hiMGL medium reduces the expression of surface receptors encoding genes P2RY12, TGF $\beta R 1, C X 3 C R 1, G P R 84$, and $C D 33$, as well as microglial transcription factors EGR1 and ETV5 [55]. In total, 24h after TGF $\beta$ treatment, more than 2000 genes were found to be differentially expressed [55]. Interestingly, many of these genes are associated with neurodegenerative diseases. The removal of TGF $\beta$ leads to significant changes that have been identified as Alzheimer's disease (AD) GWAS loci genes, including TREM2 and APOE, indicating the relevance of TGF $\beta$ for microglial homeostasis and maintenance [55]. Based on these data, pathways regulating mitosis and proliferation are also modulated by TGF $\beta$ treatment [55] similar to observations in mice [75]. Finally, the differentiation and proliferation of already differentiating hiMGLs are significantly diminished when TGF $\beta$ is withdrawn in vitro [62].

Intriguingly, TGF $\beta$ actions can be mimicked by incubation with a more stable small molecule, "Inducer of Definitive Endoderm1" (IDE1), mediating the phosphorylation of TGF $\beta$ downstream signaling [77]. It is noteworthy that the substitution of TGF $\beta$ by IDE1 results in similar growth kinetics compared with TGF $\beta$ treatment and higher IDE1 concentrations, further increasing cell proliferation. Correlation analysis demonstrates that gene expression of IDE1-treated iMGLs cluster with TGF $\beta$-treated iMGLs and even more with fetal and adult microglia [62].

Although TGF $\beta$ has not been added as a recombinant cytokine in all hiMGL protocols, the use of $10 \%$ fetal bovine serum (FBS) supplemented medium in distinct differentiation protocols might contain $1-2 \mathrm{ng} / \mathrm{mL}$ of TGF $\beta$ [78], supporting the microglia maturation process $[64,68]$. In this context, the further development of immature hiMGLs could benefit from these "hidden" TGF $\beta$ effects, and its well-described functions to regulate microglial activation might additionally play important roles [79].

\subsection{Cell-Cell and Cell-Matrix Interactions in hiMGL Differentiation and Maturation In Vitro}

Since even fine-tuned culture media do not fully reproduce the complex microglial niche in the developing three-dimensional brain, neuronal and astrocyte-derived signals have been hypothesized to influence microglial identity and may also be crucial for the generation of fully maturated hiMGLs. Principle component analysis of the transcriptome reveals that hiMGLs exposed to hiPSC-derived mature neuron-conditioned medium slightly shift their transcriptome to fetal microglia [54]. Direct co-culture with neurons results in the expression of human-specific sialic acid-binding immunoglobulin-type lectin (SIGLEC) 11 and SIGLEC 12 that interact with the neuronal glycocalyx, suppressing inflammation, and thus, may maintain microglia in a homeostatic state [55]. Additionally, the co-culture of neurons and hiMGLs results in a more dynamically ramified morphology and enhanced migration abilities, as well as an overall reduced secretion of chemokines and cytokines, indicating mechanisms of neuron-mediated homeostasis [58]. A recent study comparing neuron-astrocyte co-culture vs. monocultured iMGLs shows that microglial signature gene expression is barely different among these groups, indicating that both approaches can lead to fully differentiated microglia [76]. However, genes related to so-called "disease-associated microglia" (DAM) have been upregulated in the monoculture group, including TREM2 that is a "risk gene" for neurodegenerative diseases. This indicates that cell-cell interactions are not necessary for the differentiation and maturation of iMGLs, but for adopting a homeostatic in vivo-like state. 


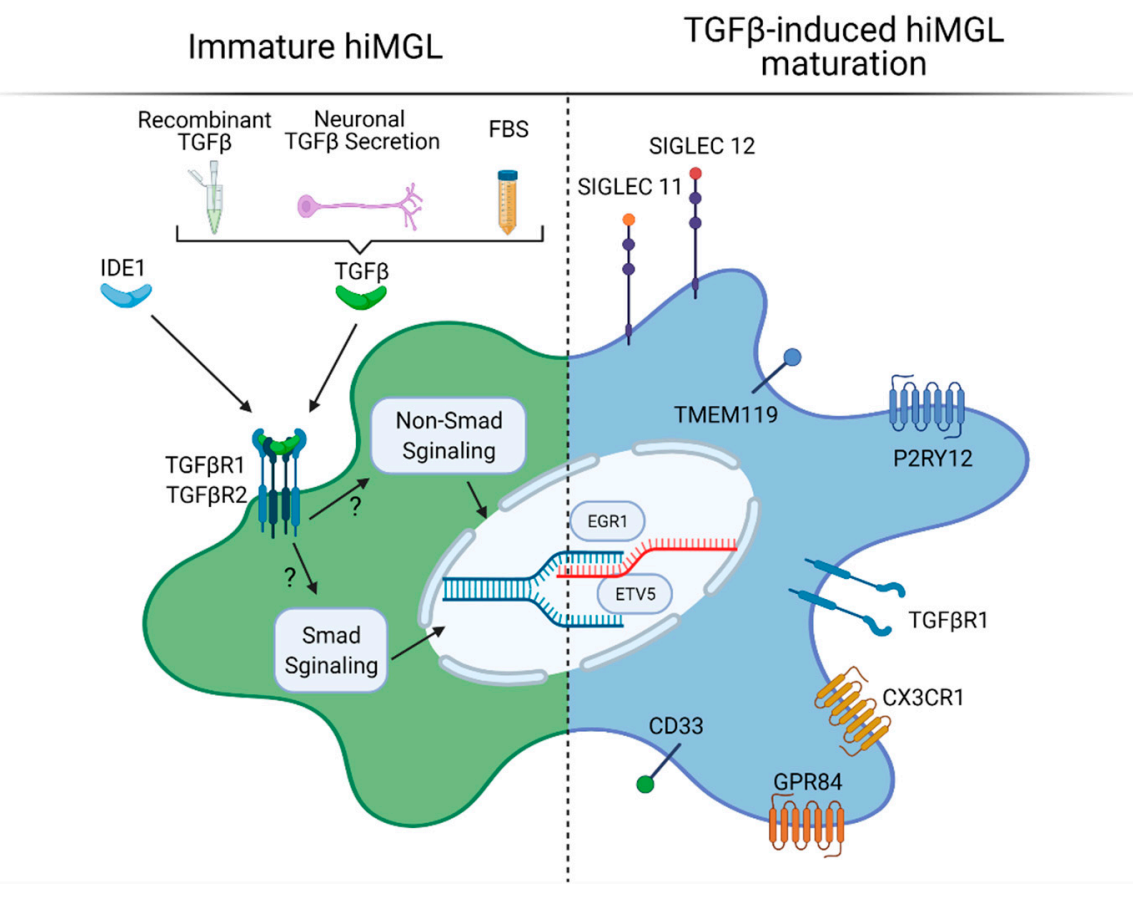

Figure 3. TGF $\beta$ effects on hiMGL maturation. The figure was created using BioRender. Available online: https:/ / biorender.com (accessed on 17 March 2021).

It has been hypothesized that the exposure of neural progenitor cell (NPC)-conditioned medium to developing hiMGLs might mimic the environmental cues as microglia develop in synchrony with neurons [65]. In fact, hiMGL maturation with NPC-conditioned medium results in the higher expression of TMEM119 compared with unconditioned media or astrocyte and oligodendrocyte precursor-conditioned media.

Although not further investigated, TGF $\beta$ signaling may be partly responsible for these effects, as this factor is continuously secreted by developing and adult neural tissue $[18,23,80]$. However, the molecular mechanisms of direct and indirect interactions of hiPSCs with neural cells boosting their differentiation and maturation for in vitro applications remain to be studied in more detail.

Additional factors affecting iMGL differentiation and maturation have been analyzed in single studies, i.e., addressing the potential of the extracellular matrix. In fact, fibronectin coating results in a more ramified morphology compared to poly-D-lsine, collagen I, gelatin, and laminin coating. Furthermore, additional treatment with (soluble) CD200 and chemokine (C-X3-C motif) ligand 1 (CX3CL1) in combination did only result in minor changes of microglia signature genes, indicating that these factors influence microglial functions rather than differentiation or maturation $[55,76]$.

\section{Summary and Conclusions}

Taken together, the generation of hiMGLs from hiPSC closely resembles the welldescribed microglia differentiation and maturation processes observed in mice and thus might represent a powerful tool for studying the functional aspects of human microglia. However, the prerequisite for such studies using hiMGLs is that these in vitro generated cells share the full molecular signatures as their in vivo counterparts. To overcome the limitations of human in vivo studies, comparative analysis of hiMGLs and mouse-derived iMGLs should be performed, examining common and divergent maturation pathways.

For a better understanding of specific developmental and maturation mechanisms, the molecular crosstalk of (how certain known and unknown) homeostatic and maturation modulators guiding the specification of microglial phenotypes at certain developmental stages and in different brain regions in mice should be dissected in more detail. The subsequent translation of these investigations to differentiation protocols will pave the 
way for a reliable and more robust in vitro generation of microglia sharing the typical expression signature, as well as functionality with their in vivo counterparts. This will also be a prerequisite for the deeper understanding of the molecular background of (human) microglia, including their putative contribution to neurodegenerative diseases. This point will be even more relevant for the possibility to employ hiMGLs for future microglia replacement strategies.

In particular, recent achievements underlining the importance of TGF $\beta 1$ and microglial TGF $\beta$ signaling need to be considered in hiMGL differentiation protocols, and further studies addressing the specific effects of TGF $\beta 1$ in human microglia and hiMGLs have to be performed in order to elucidate the molecular mechanisms underlying TGF $\beta 1$-mediated effects. Moreover, the benefit of TGF $\beta 1$ as an additional factor for hiMGL maturation has to be analyzed and validated in more detail in order to generate hiMGLs that share essential features of human microglia in vivo.

Author Contributions: J.W. and B.S. drafted the manuscript, and prepared the figures; J.W., B.S., H.K., C.A. and T.M. performed the literature review, edited the manuscript and provided conceptual guidance. All authors have read and agreed to the published version of the manuscript.

Funding: We acknowledge support for the publication costs by the Open Access Publication Fund of Bielefeld University.

Institutional Review Board Statement: Not Applicable.

Informed Consent Statement: Not Applicable.

Data Availability Statement: Not Applicable.

Conflicts of Interest: The authors declare no conflict of interest.

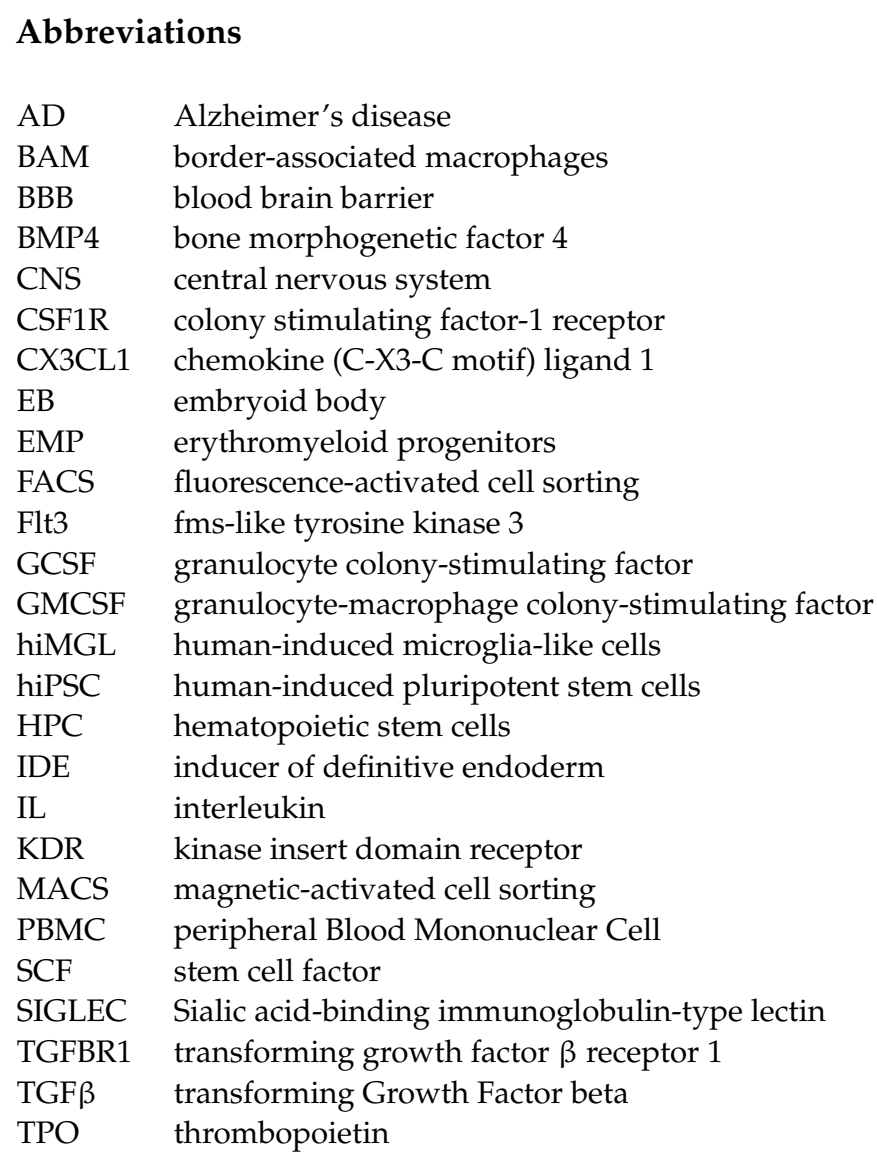




\section{References}

1. Ginhoux, F.; Greter, M.; Leboeuf, M.; Nandi, S.; See, P.; Gokhan, S.; Mehler, M.F.; Conway, S.J.; Ng, L.G.; Stanley, E.R.; et al. Fate Mapping Analysis Reveals That Adult Microglia Derive from Primitive Macrophages. Science 2010, 330, 841-845. [CrossRef] [PubMed]

2. Kierdorf, K.; Erny, D.; Goldmann, T.; Sander, V.; Schulz, C.; Perdiguero, E.G.; Wieghofer, P.; Heinrich, A.; Riemke, P.; Hölscher, C.; et al. Microglia Emerge from Erythromyeloid Precursors via Pu.1- and Irf8-Dependent Pathways. Nat. Neurosci. 2013, 16, 273-280. [CrossRef]

3. Schulz, C.; Gomez Perdiguero, E.; Chorro, L.; Szabo-Rogers, H.; Cagnard, N.; Kierdorf, K.; Prinz, M.; Wu, B.; Jacobsen, S.E.W.; Pollard, J.W.; et al. A Lineage of Myeloid Cells Independent of Myb and Hematopoietic Stem Cells. Science 2012, 336, 86-90. [CrossRef] [PubMed]

4. Gomez Perdiguero, E.; Klapproth, K.; Schulz, C.; Busch, K.; Azzoni, E.; Crozet, L.; Garner, H.; Trouillet, C.; de Bruijn, M.F.; Geissmann, F.; et al. Tissue-Resident Macrophages Originate from Yolk-Sac-Derived Erythro-Myeloid Progenitors. Nature 2015, 518, 547-551. [CrossRef]

5. Greter, M.; Lelios, I.; Pelczar, P.; Hoeffel, G.; Price, J.; Leboeuf, M.; Kündig, T.M.; Frei, K.; Ginhoux, F.; Merad, M.; et al. StromaDerived Interleukin-34 Controls the Development and Maintenance of Langerhans Cells and the Maintenance of Microglia. Immunity 2012, 37, 1050-1060. [CrossRef]

6. $\quad$ Elmore, M.R.P.; Najafi, A.R.; Koike, M.A.; Dagher, N.N.; Spangenberg, E.E.; Rice, R.A.; Kitazawa, M.; Matusow, B.; Nguyen, H.; West, B.L.; et al. Colony-Stimulating Factor 1 Receptor Signaling Is Necessary for Microglia Viability, Unmasking a Microglia Progenitor Cell in the Adult Brain. Neuron 2014, 82, 380-397. [CrossRef]

7. Lavin, Y.; Winter, D.; Blecher-Gonen, R.; David, E.; Keren-Shaul, H.; Merad, M.; Jung, S.; Amit, I. Tissue-Resident Macrophage Enhancer Landscapes Are Shaped by the Local Microenvironment. Cell 2014, 159, 1312-1326. [CrossRef] [PubMed]

8. Gosselin, D.; Link, V.M.; Romanoski, C.E.; Fonseca, G.J.; Eichenfield, D.Z.; Spann, N.J.; Stender, J.D.; Chun, H.B.; Garner, H.; Geissmann, F.; et al. Environment Drives Selection and Function of Enhancers Controlling Tissue-Specific Macrophage Identities. Cell 2014, 159, 1327-1340. [CrossRef] [PubMed]

9. Buttgereit, A.; Lelios, I.; Yu, X.; Vrohlings, M.; Krakoski, N.R.; Gautier, E.L.; Nishinakamura, R.; Becher, B.; Greter, M. Sall1 Is a Transcriptional Regulator Defining Microglia Identity and Function. Nat. Immunol. 2016, 17, 1397-1406. [CrossRef]

10. Sharaf, A.; Krieglstein, K.; Spittau, B. Distribution of Microglia in the Postnatal Murine Nigrostriatal System. Cell Tissue Res. 2013, 351, 373-382. [CrossRef]

11. Askew, K.; Li, K.; Olmos-Alonso, A.; Garcia-Moreno, F.; Liang, Y.; Richardson, P.; Tipton, T.; Chapman, M.A.; Riecken, K.; Beccari, S.; et al. Coupled Proliferation and Apoptosis Maintain the Rapid Turnover of Microglia in the Adult Brain. Cell Rep. 2017, 18, 391-405. [CrossRef]

12. Ajami, B.; Bennett, J.L.; Krieger, C.; McNagny, K.M.; Rossi, F.M.V. Infiltrating Monocytes Trigger EAE Progression, but Do Not Contribute to the Resident Microglia Pool. Nat. Neurosci. 2011, 14, 1142-1149. [CrossRef] [PubMed]

13. Ajami, B.; Bennett, J.L.; Krieger, C.; Tetzlaff, W.; Rossi, F.M.V. Local Self-Renewal Can Sustain CNS Microglia Maintenance and Function throughout Adult Life. Nat. Neurosci. 2007, 10, 1538-1543. [CrossRef] [PubMed]

14. Matcovitch-Natan, O.; Winter, D.R.; Giladi, A.; Vargas Aguilar, S.; Spinrad, A.; Sarrazin, S.; Ben-Yehuda, H.; David, E.; Zelada González, F.; Perrin, P.; et al. Microglia Development Follows a Stepwise Program to Regulate Brain Homeostasis. Science 2016, 353, aad8670. [CrossRef] [PubMed]

15. Thion, M.S.; Low, D.; Silvin, A.; Chen, J.; Grisel, P.; Schulte-Schrepping, J.; Blecher, R.; Ulas, T.; Squarzoni, P.; Hoeffel, G.; et al. Microbiome Influences Prenatal and Adult Microglia in a Sex-Specific Manner. Cell 2018, 172, 500-516.e16. [CrossRef]

16. Bennett, M.L.; Bennett, F.C.; Liddelow, S.A.; Ajami, B.; Zamanian, J.L.; Fernhoff, N.B.; Mulinyawe, S.B.; Bohlen, C.J.; Adil, A.; Tucker, A.; et al. New Tools for Studying Microglia in the Mouse and Human CNS. Proc. Natl. Acad. Sci. USA 2016, 113, E1738-E1746. [CrossRef] [PubMed]

17. Butovsky, O.; Jedrychowski, M.P.; Moore, C.S.; Cialic, R.; Lanser, A.J.; Gabriely, G.; Koeglsperger, T.; Dake, B.; Wu, P.M.; Doykan, C.E.; et al. Identification of a Unique TGF- $\beta$-Dependent Molecular and Functional Signature in Microglia. Nat. Neurosci. 2014, 17, 131-143. [CrossRef] [PubMed]

18. Attaai, A.; Neidert, N.; von Ehr, A.; Potru, P.S.; Zöller, T.; Spittau, B. Postnatal Maturation of Microglia Is Associated with Alternative Activation and Activated TGF $\beta$ Signaling. Glia 2018, 66, 1695-1708. [CrossRef]

19. Beutner, C.; Linnartz-Gerlach, B.; Schmidt, S.V.; Beyer, M.; Mallmann, M.R.; Staratschek-Jox, A.; Schultze, J.L.; Neumann, H. Unique Transcriptome Signature of Mouse Microglia. Glia 2013, 61, 1429-1442. [CrossRef]

20. Masuda, T.; Amann, L.; Sankowski, R.; Staszewski, O.; Lenz, M.; d'Errico, P.; Snaidero, N.; Costa Jordão, M.J.; Böttcher, C.; Kierdorf, K.; et al. Novel Hexb-Based Tools for Studying Microglia in the CNS. Nat. Immunol. 2020, 21, 802-815. [CrossRef]

21. Hickman, S.E.; Kingery, N.D.; Ohsumi, T.K.; Borowsky, M.L.; Wang, L.; Means, T.K.; El Khoury, J. The Microglial Sensome Revealed by Direct RNA Sequencing. Nat. Neurosci. 2013, 16, 1896-1905. [CrossRef] [PubMed]

22. Butovsky, O.; Weiner, H.L. Microglial Signatures and Their Role in Health and Disease. Nat. Rev. Neurosci. 2018, 19, 622-635. [CrossRef]

23. Liu, Y.; Aguzzi, A. NG2 Glia Are Required for Maintaining Microglia Homeostatic State. Glia 2019, 68, 345-355. [CrossRef] 
24. Utz, S.G.; See, P.; Mildenberger, W.; Thion, M.S.; Silvin, A.; Lutz, M.; Ingelfinger, F.; Rayan, N.A.; Lelios, I.; Buttgereit, A.; et al. Early Fate Defines Microglia and Non-Parenchymal Brain Macrophage Development. Cell 2020, 181, 557-573.e18. [CrossRef] [PubMed]

25. Spittau, B.; Dokalis, N.; Prinz, M. The Role of TGF $\beta$ Signaling in Microglia Maturation and Activation. Trends Immunol. 2020, 41, 836-848. [CrossRef]

26. Aluwihare, P.; Mu, Z.; Zhao, Z.; Yu, D.; Weinreb, P.H.; Horan, G.S.; Violette, S.M.; Munger, J.S. Mice That Lack Activity of Alphavbeta6- and Alphavbeta8-Integrins Reproduce the Abnormalities of Tgfb1- and Tgfb3-Null Mice. J. Cell. Sci. 2009, 122, 227-232. [CrossRef] [PubMed]

27. Qin, Y.; Garrison, B.S.; Ma, W.; Wang, R.; Jiang, A.; Li, J.; Mistry, M.; Bronson, R.T.; Santoro, D.; Franco, C.; et al. A Milieu Molecule for TGF- $\beta$ Required for Microglia Function in the Nervous System. Cell 2018, 174, 156-171.e16. [CrossRef] [PubMed]

28. Arnold, T.D.; Lizama, C.O.; Cautivo, K.M.; Santander, N.; Lin, L.; Qiu, H.; Huang, E.J.; Liu, C.; Mukouyama, Y.-S.; Reichardt, L.F.; et al. Impaired AV $\beta 8$ and TGF $\beta$ Signaling Lead to Microglial Dysmaturation and Neuromotor Dysfunction. J. Exp. Med. 2019, 216, 900-915. [CrossRef]

29. Zöller, T.; Schneider, A.; Kleimeyer, C.; Masuda, T.; Potru, P.S.; Pfeifer, D.; Blank, T.; Prinz, M.; Spittau, B. Silencing of TGF $\beta$ Signalling in Microglia Results in Impaired Homeostasis. Nat. Commun. 2018, 9, 4011. [CrossRef] [PubMed]

30. Cserép, C.; Pósfai, B.; Lénárt, N.; Fekete, R.; László, Z.I.; Lele, Z.; Orsolits, B.; Molnár, G.; Heindl, S.; Schwarcz, A.D.; et al. Microglia Monitor and Protect Neuronal Function through Specialized Somatic Purinergic Junctions. Science 2020, 367, 528-537. [CrossRef] [PubMed]

31. Lou, N.; Takano, T.; Pei, Y.; Xavier, A.L.; Goldman, S.A.; Nedergaard, M. Purinergic Receptor P2RY12-Dependent Microglial Closure of the Injured Blood-Brain Barrier. Proc. Natl. Acad. Sci. USA 2016, 113, 1074-1079. [CrossRef]

32. Vainchtein, I.D.; Chin, G.; Cho, F.S.; Kelley, K.W.; Miller, J.G.; Chien, E.C.; Liddelow, S.A.; Nguyen, P.T.; Nakao-Inoue, H.; Dorman, L.C.; et al. Astrocyte-Derived Interleukin-33 Promotes Microglial Synapse Engulfment and Neural Circuit Development. Science 2018, 359, 1269-1273. [CrossRef]

33. Pasciuto, E.; Burton, O.T.; Roca, C.P.; Lagou, V.; Rajan, W.D.; Theys, T.; Mancuso, R.; Tito, R.Y.; Kouser, L.; Callaerts-Vegh, Z.; et al. Microglia Require CD4 T Cells to Complete the Fetal-to-Adult Transition. Cell 2020, 182, 625-640.e24. [CrossRef] [PubMed]

34. Block, M.L.; Zecca, L.; Hong, J.-S. Microglia-Mediated Neurotoxicity: Uncovering the Molecular Mechanisms. Nat. Rev. Neurosci. 2007, 8, 57-69. [CrossRef] [PubMed]

35. Stevens, B.; Allen, N.J.; Vazquez, L.E.; Howell, G.R.; Christopherson, K.S.; Nouri, N.; Micheva, K.D.; Mehalow, A.K.; Huberman, A.D.; Stafford, B.; et al. The Classical Complement Cascade Mediates CNS Synapse Elimination. Cell 2007, 131, 1164-1178. [CrossRef] [PubMed]

36. Paolicelli, R.C.; Bolasco, G.; Pagani, F.; Maggi, L.; Scianni, M.; Panzanelli, P.; Giustetto, M.; Ferreira, T.A.; Guiducci, E.; Dumas, L.; et al. Synaptic Pruning by Microglia Is Necessary for Normal Brain Development. Science 2011, 333, 1456-1458. [CrossRef] [PubMed]

37. Schafer, D.P.; Lehrman, E.K.; Kautzman, A.G.; Koyama, R.; Mardinly, A.R.; Yamasaki, R.; Ransohoff, R.M.; Greenberg, M.E.; Barres, B.A.; Stevens, B. Microglia Sculpt Postnatal Neural Circuits in an Activity and Complement-Dependent Manner. Neuron 2012, 74, 691-705. [CrossRef]

38. Ueno, M.; Fujita, Y.; Tanaka, T.; Nakamura, Y.; Kikuta, J.; Ishii, M.; Yamashita, T. Layer V Cortical Neurons Require Microglial Support for Survival during Postnatal Development. Nat. Neurosci. 2013, 16, 543-551. [CrossRef] [PubMed]

39. Hagemeyer, N.; Hanft, K.-M.; Akriditou, M.-A.; Unger, N.; Park, E.S.; Stanley, E.R.; Staszewski, O.; Dimou, L.; Prinz, M. Microglia Contribute to Normal Myelinogenesis and to Oligodendrocyte Progenitor Maintenance during Adulthood. Acta Neuropathol. 2017, 134, 441-458. [CrossRef]

40. Parkhurst, C.N.; Yang, G.; Ninan, I.; Savas, J.N.; Yates, J.R.; Lafaille, J.J.; Hempstead, B.L.; Littman, D.R.; Gan, W.-B. Microglia Promote Learning-Dependent Synapse Formation through Brain-Derived Neurotrophic Factor. Cell 2013, 155, 1596-1609. [CrossRef]

41. Wang, X.; Zhao, L.; Zhang, J.; Fariss, R.N.; Ma, W.; Kretschmer, F.; Wang, M.; Qian, H.H.; Badea, T.C.; Diamond, J.S.; et al. Requirement for Microglia for the Maintenance of Synaptic Function and Integrity in the Mature Retina. J. Neurosci. 2016, 36, 2827-2842. [CrossRef] [PubMed]

42. Kracht, L.; Borggrewe, M.; Eskandar, S.; Brouwer, N.; Lopes, S.M.C.D.S.; Laman, J.D.; Scherjon, S.A.; Prins, J.R.; Kooistra, S.M.; Eggen, B.J.L. Human Fetal Microglia Acquire Homeostatic Immune-Sensing Properties Early in Development. Science 2020, 369, 530-537. [CrossRef]

43. Bian, Z.; Gong, Y.; Huang, T.; Lee, C.Z.W.; Bian, L.; Bai, Z.; Shi, H.; Zeng, Y.; Liu, C.; He, J.; et al. Deciphering Human Macrophage Development at Single-Cell Resolution. Nature 2020, 582, 571-576. [CrossRef]

44. Smith, A.M.; Graham, E.S.; Feng, S.X.; Oldfield, R.L.; Bergin, P.M.; Mee, E.W.; Faull, R.L.M.; Curtis, M.A.; Dragunow, M. Adult Human Glia, Pericytes and Meningeal Fibroblasts Respond Similarly to IFNy but Not to TGF 31 or M-CSF. PLoS ONE 2013, 8, e80463. [CrossRef]

45. Galatro, T.F.; Holtman, I.R.; Lerario, A.M.; Vainchtein, I.D.; Brouwer, N.; Sola, P.R.; Veras, M.M.; Pereira, T.F.; Leite, R.E.P.; Möller, T.; et al. Transcriptomic Analysis of Purified Human Cortical Microglia Reveals Age-Associated Changes. Nat. Neurosci. 2017, 20, 1162-1171. [CrossRef] [PubMed] 
46. Hayakawa, T.; Angata, T.; Lewis, A.L.; Mikkelsen, T.S.; Varki, N.M.; Varki, A. A Human-Specific Gene in Microglia. Science 2005, 309, 1693. [CrossRef] [PubMed]

47. Brinkman-Van der Linden, E.C.M.; Angata, T.; Reynolds, S.A.; Powell, L.D.; Hedrick, S.M.; Varki, A. CD33/Siglec-3 Binding Specificity, Expression Pattern, and Consequences of Gene Deletion in Mice. Mol. Cell Biol. 2003, 23, 4199-4206. [CrossRef] [PubMed]

48. Gibbons, H.M.; Hughes, S.M.; Van Roon-Mom, W.; Greenwood, J.M.; Narayan, P.J.; Teoh, H.H.; Bergin, P.M.; Mee, E.W.; Wood, P.C.; Faull, R.L.M.; et al. Cellular Composition of Human Glial Cultures from Adult Biopsy Brain Tissue. J. Neurosci. Methods 2007, 166, 89-98. [CrossRef] [PubMed]

49. Marshall, G.P.; Demir, M.; Steindler, D.A.; Laywell, E.D. Subventricular Zone Microglia Possess a Unique Capacity for Massive in Vitro Expansion. Glia 2008, 56, 1799-1808. [CrossRef]

50. Garcia-Mesa, Y.; Jay, T.R.; Checkley, M.A.; Luttge, B.; Dobrowolski, C.; Valadkhan, S.; Landreth, G.E.; Karn, J.; Alvarez-Carbonell, D. Immortalization of Primary Microglia: A New Platform to Study HIV Regulation in the Central Nervous System. J. Neurovirol. 2017, 23, 47-66. [CrossRef]

51. Nagai, A.; Nakagawa, E.; Hatori, K.; Choi, H.B.; McLarnon, J.G.; Lee, M.A.; Kim, S.U. Generation and Characterization of Immortalized Human Microglial Cell Lines: Expression of Cytokines and Chemokines. Neurobiol. Dis. 2001, 8, 1057-1068. [CrossRef]

52. Janabi, N.; Peudenier, S.; Héron, B.; Ng, K.H.; Tardieu, M. Establishment of Human Microglial Cell Lines after Transfection of Primary Cultures of Embryonic Microglial Cells with the SV40 Large T Antigen. Neurosci. Lett. 1995, 195, 105-108. [CrossRef]

53. Dello Russo, C.; Cappoli, N.; Coletta, I.; Mezzogori, D.; Paciello, F.; Pozzoli, G.; Navarra, P.; Battaglia, A. The Human Microglial HMC3 Cell Line: Where Do We Stand? A Systematic Literature Review. J. Neuroinflamm. 2018, 15, 259. [CrossRef]

54. Muffat, J.; Li, Y.; Yuan, B.; Mitalipova, M.; Omer, A.; Corcoran, S.; Bakiasi, G.; Tsai, L.-H.; Aubourg, P.; Ransohoff, R.M.; et al Efficient Derivation of Microglia-like Cells from Human Pluripotent Stem Cells. Nat. Med. 2016, 22, 1358-1367. [CrossRef] [PubMed]

55. Abud, E.M.; Ramirez, R.N.; Martinez, E.S.; Healy, L.M.; Nguyen, C.H.H.; Newman, S.A.; Yeromin, A.V.; Scarfone, V.M.; Marsh, S.E.; Fimbres, C.; et al. IPSC-Derived Human Microglia-like Cells to Study Neurological Diseases. Neuron 2017, 94, 278-293.e9. [CrossRef] [PubMed]

56. Amos, P.J.; Fung, S.; Case, A.; Kifelew, J.; Osnis, L.; Smith, C.L.; Green, K.; Naydenov, A.; Aloi, M.; Hubbard, J.J.; et al. Modulation of Hematopoietic Lineage Specification Impacts TREM2 Expression in Microglia-Like Cells Derived From Human Stem Cells. ASN Neuro 2017, 9, 1759091417716610. [CrossRef] [PubMed]

57. Douvaras, P.; Sun, B.; Wang, M.; Kruglikov, I.; Lallos, G.; Zimmer, M.; Terrenoire, C.; Zhang, B.; Gandy, S.; Schadt, E.; et al. Directed Differentiation of Human Pluripotent Stem Cells to Microglia. Stem Cell Rep. 2017, 8, 1516-1524. [CrossRef]

58. Haenseler, W.; Sansom, S.N.; Buchrieser, J.; Newey, S.E.; Moore, C.S.; Nicholls, F.J.; Chintawar, S.; Schnell, C.; Antel, J.P.; Allen, N.D.; et al. A Highly Efficient Human Pluripotent Stem Cell Microglia Model Displays a Neuronal-Co-Culture-Specific Expression Profile and Inflammatory Response. Stem Cell Rep. 2017, 8, 1727-1742. [CrossRef] [PubMed]

59. Pandya, H.; Shen, M.J.; Ichikawa, D.M.; Sedlock, A.B.; Choi, Y.; Johnson, K.R.; Kim, G.; Brown, M.A.; Elkahloun, A.G.; Maric, D.; et al. Differentiation of Human and Murine Induced Pluripotent Stem Cells to Microglia-like Cells. Nat. Neurosci. 2017, 20, 753-759. [CrossRef]

60. Takata, K.; Kozaki, T.; Lee, C.Z.W.; Thion, M.S.; Otsuka, M.; Lim, S.; Utami, K.H.; Fidan, K.; Park, D.S.; Malleret, B.; et al. Induced-Pluripotent-Stem-Cell-Derived Primitive Macrophages Provide a Platform for Modeling Tissue-Resident Macrophage Differentiation and Function. Immunity 2017, 47, 183-198.e6. [CrossRef]

61. Brownjohn, P.W.; Smith, J.; Solanki, R.; Lohmann, E.; Houlden, H.; Hardy, J.; Dietmann, S.; Livesey, F.J. Functional Studies of Missense TREM2 Mutations in Human Stem Cell-Derived Microglia. Stem Cell Rep. 2018, 10, 1294-1307. [CrossRef]

62. McQuade, A.; Coburn, M.; Tu, C.H.; Hasselmann, J.; Davtyan, H.; Blurton-Jones, M. Development and Validation of a Simplified Method to Generate Human Microglia from Pluripotent Stem Cells. Mol. Neurodegener. 2018, 13, 67. [CrossRef]

63. Claes, C.; Van Den Daele, J.; Boon, R.; Schouteden, S.; Colombo, A.; Monasor, L.S.; Fiers, M.; Ordovás, L.; Nami, F.; Bohrmann, B.; et al. Human Stem Cell-Derived Monocytes and Microglia-like Cells Reveal Impaired Amyloid Plaque Clearance upon Heterozygous or Homozygous Loss of TREM2. Alzheimers Dement 2019, 15, 453-464. [CrossRef]

64. Konttinen, H.; Cabral-da-Silva, M.E.C.; Ohtonen, S.; Wojciechowski, S.; Shakirzyanova, A.; Caligola, S.; Giugno, R.; Ishchenko, Y.; Hernández, D.; Fazaludeen, M.F.; et al. PSEN1 $\mathrm{E} 9$, APPswe, and APOE4 Confer Disparate Phenotypes in Human IPSC-Derived Microglia. Stem Cell Rep. 2019, 13, 669-683. [CrossRef] [PubMed]

65. Banerjee, P.; Paza, E.; Perkins, E.M.; James, O.G.; Kenkhuis, B.; Lloyd, A.F.; Burr, K.; Story, D.; Yusuf, D.; He, X.; et al. Generation of Pure Monocultures of Human Microglia-like Cells from Induced Pluripotent Stem Cells. Stem Cell Res. 2020, $49,102046$. [CrossRef] [PubMed]

66. Cheng, X.; Huber, T.L.; Chen, V.C.; Gadue, P.; Keller, G.M. Numb Mediates the Interaction between Wnt and Notch to Modulate Primitive Erythropoietic Specification from the Hemangioblast. Development 2008, 135, 3447-3458. [CrossRef]

67. Sturgeon, C.M.; Ditadi, A.; Awong, G.; Kennedy, M.; Keller, G. Wnt Signaling Controls the Specification of Definitive and Primitive Hematopoiesis from Human Pluripotent Stem Cells. Nat. Biotechnol. 2014, 32, 554-561. [CrossRef] 
68. Guttikonda, S.R.; Sikkema, L.; Tchieu, J.; Saurat, N.; Walsh, R.M.; Harschnitz, O.; Ciceri, G.; Sneeboer, M.; Mazutis, L.; Setty, M.; et al. Fully Defined Human Pluripotent Stem Cell-Derived Microglia and Tri-Culture System Model C3 Production in Alzheimer's Disease. Nat. Neurosci. 2021, 24, 343-354. [CrossRef] [PubMed]

69. Song, L.; Yuan, X.; Jones, Z.; Vied, C.; Miao, Y.; Marzano, M.; Hua, T.; Sang, Q.-X.A.; Guan, J.; Ma, T.; et al. Functionalization of Brain Region-Specific Spheroids with Isogenic Microglia-like Cells. Sci. Rep. 2019, 9, 11055. [CrossRef]

70. Winkle, A.P.V.; Gates, I.D.; Kallos, M.S. Mass Transfer Limitations in Embryoid Bodies during Human Embryonic Stem Cell Differentiation. CTO 2012, 196, 34-47. [CrossRef]

71. Wei, S.; Nandi, S.; Chitu, V.; Yeung, Y.-G.; Yu, W.; Huang, M.; Williams, L.T.; Lin, H.; Stanley, E.R. Functional Overlap but Differential Expression of CSF-1 and IL-34 in Their CSF-1 Receptor-Mediated Regulation of Myeloid Cells. J. Leukoc. Biol. 2010, 88, 495-505. [CrossRef]

72. Wang, Y.; Szretter, K.J.; Vermi, W.; Gilfillan, S.; Rossini, C.; Cella, M.; Barrow, A.D.; Diamond, M.S.; Colonna, M. IL-34 Is a Tissue-Restricted Ligand of CSF1R Required for the Development of Langerhans Cells and Microglia. Nat. Immunol. 2012, 13, 753-760. [CrossRef]

73. Svoboda, D.S.; Barrasa, M.I.; Shu, J.; Rietjens, R.; Zhang, S.; Mitalipova, M.; Berube, P.; Fu, D.; Shultz, L.D.; Bell, G.W.; et al. Human IPSC-Derived Microglia Assume a Primary Microglia-like State after Transplantation into the Neonatal Mouse Brain. Proc. Natl. Acad. Sci. USA 2019, 116, 25293-25303. [CrossRef] [PubMed]

74. Choi, S.S.; Lee, H.J.; Lim, I.; Satoh, J.; Kim, S.U. Human Astrocytes: Secretome Profiles of Cytokines and Chemokines. PLoS ONE 2014, 9, e92325. [CrossRef] [PubMed]

75. Abutbul, S.; Shapiro, J.; Szaingurten-Solodkin, I.; Levy, N.; Carmy, Y.; Baron, R.; Jung, S.; Monsonego, A. TGF- $\beta$ Signaling through SMAD2/3 Induces the Quiescent Microglial Phenotype within the CNS Environment. Glia 2012, 60, 1160-1171. [CrossRef] [PubMed]

76. Reich, M.; Paris, I.; Ebeling, M.; Dahm, N.; Schweitzer, C.; Reinhardt, D.; Schmucki, R.; Prasad, M.; Köchl, F.; Leist, M.; et al. Alzheimer's Risk Gene TREM2 Determines Functional Properties of New Type of Human IPSC-Derived Microglia. Front. Immunol. 2021, 11, 3918. [CrossRef] [PubMed]

77. Borowiak, M.; Maehr, R.; Chen, S.; Chen, A.E.; Tang, W.; Fox, J.L.; Schreiber, S.L.; Melton, D.A. Small Molecules Efficiently Direct Endodermal Differentiation of Mouse and Human Embryonic Stem Cells. Cell Stem Cell 2009, 4, 348-358. [CrossRef]

78. Oida, T.; Weiner, H.L. Depletion of TGF- $\beta$ from Fetal Bovine Serum. J. Immunol. Methods 2010, 362, 195-198. [CrossRef]

79. Yao, Y.; Fu, K.-Y. Serum-deprivation Leads to Activation-Like Changes in Primary Microglia and BV-2 Cells but Not Astrocytes. Biomed. Rep. 2020, 13, 1. [CrossRef]

80. Diniz, L.P.; Tortelli, V.; Matias, I.; Morgado, J.; Bérgamo Araujo, A.P.; Melo, H.M.; Seixas da Silva, G.S.; Alves-Leon, S.V.; de Souza, J.M.; Ferreira, S.T.; et al. Astrocyte Transforming Growth Factor Beta 1 Protects Synapses against A $\beta$ Oligomers in Alzheimer's Disease Model. J. Neurosci. 2017, 37, 6797-6809. [CrossRef] 